\title{
Olfactory discrimination predicts cognitive decline among community-dwelling older adults
}

\author{
HR Sohrabi ${ }^{1,2,3}$, KA Bates ${ }^{2,3,4}$, MG Weinborn ${ }^{5}$, ANB Johnston ${ }^{6}$, A Bahramian ${ }^{2}, K_{\text {Taddei }}{ }^{1,2,3}$, SM Laws ${ }^{1,2,3}$, M Rodrigues ${ }^{1,2}$, \\ M Morici $^{1}$, M Howard ${ }^{1}$, G Martins ${ }^{1,2}$, A Mackay-Sim ${ }^{6}$, SE Gandy ${ }^{7}$ and RN Martins ${ }^{1,2,3,8}$
}

The presence of olfactory dysfunction in individuals at higher risk of Alzheimer's disease has significant diagnostic and screening implications for preventive and ameliorative drug trials. Olfactory threshold, discrimination and identification can be reliably recorded in the early stages of neurodegenerative diseases. The current study has examined the ability of various olfactory functions in predicting cognitive decline in a community-dwelling sample. A group of 308 participants, aged 46-86 years old, were recruited for this study. After 3 years of follow-up, participants were divided into cognitively declined and non-declined groups based on their performance on a neuropsychological battery. Assessment of olfactory functions using the Sniffin' Sticks battery indicated that, contrary to previous findings, olfactory discrimination, but not olfactory identification, significantly predicted subsequent cognitive decline (odds ratio $=0.869 ; P<0.05 ; 95 \%$ confidence interval $=0.764-0.988$ ). The current study findings confirm previously reported associations between olfactory and cognitive functions, and indicate that impairment in olfactory discrimination can predict future cognitive decline. These findings further our current understanding of the association between cognition and olfaction, and support olfactory assessment in screening those at higher risk of dementia.

Translational Psychiatry (2012) 2, e118; doi:10.1038/tp.2012.43; published online 22 May 2012

\section{Introduction}

Olfactory dysfunction has been reliably demonstrated in Alzheimer's disease $(A D)^{1-3}$ and mild cognitive impairment. ${ }^{4,5}$ Of note, olfactory impairment has also been reported in cognitively healthy individuals positive for apolipoprotein $E \& 4$ $(A P O E-\varepsilon 4)$ allele, the main genetic risk factor for $A D,{ }^{6,7}$ as well as in those with another potential risk factor for $A D$, namely subjective memory complaints. ${ }^{8}$

Indeed, olfactory dysfunction has been significantly associated with the risk of future $A D$ and $A D$ neuropathology burden in the brain. ${ }^{9} \mathrm{AD}$-related neuropathological studies of animals and humans have indicated the following: (i) A negative association between amyloid-beta ( $\beta$-amyloid) load in the brain and olfaction; ${ }^{10-12}$ (ii) $\mathrm{A}$ strong association between tau pathology in olfactory system, Braak staging of $A D$ pathology and cognitive decline; ${ }^{3,14}$ and (iii) Presence of oxidative damage in the olfactory epithelium in the early stages of AD. ${ }^{15,16}$

Observational and clinical studies have found a significant association between olfactory impairment and subsequent cognitive decline. For example, a large-scale study $(N=1920)$ on the relationship between olfactory identification ability and general cognitive functioning (as measured by Mini Mental State Examination (MMSE)) indicated that olfactory dysfunction at baseline was significantly predictive of future cognitive impairment after 5 years (odds ratio $(O R)=6.62$; confidence interval $(\mathrm{Cl})=4.36-10.04) .{ }^{17}$ Schubert et al. ${ }^{17}$ have also reported low sensitivity of $55.1 \%$ but high specificity (84.4\%) for olfactory assessment in predicting cognitive decline.

However, the olfaction/cognition relationship has not been consistently found, particularly when more complicated olfactory assessment instruments including electrophysiological measures were used in addition to psychophysical methods. ${ }^{18}$ Indeed, the different methods utilized to assess olfaction may be responsible for the inconsistent findings. ${ }^{19}$ Olfactory abilities are primarily assessed by measuring threshold (lowest detectable concentration of odors), discrimination (ability to differentiate between odors) and identification (ability to identify odors). ${ }^{20}$ It has been suggested that olfactory threshold is strongly related to sensory capability, while olfactory discrimination and identification are more closely associated with higher cognitive functions, and thus may be more cognitively loaded. ${ }^{8,21} \mathrm{~A}$ dated, but still informative, review has reported a strong association between cognitive functions and certain aspects of olfactory functioning, concluding that compared with the ability to detect odors, identification of odors is more challenging, perhaps due to a lack of access to verbal or visual representations of odors. ${ }^{22}$ Similarly, Schab ${ }^{23}$ noted that odor identification may represent a semantic memory function. Some researchers suggest that olfactory identification is primarily predictive of memory decline. ${ }^{24}$ It is interesting that while verbal and visual cues

\footnotetext{
${ }^{1}$ The School of Medical Sciences, Edith Cowan University, Joondalup, WA, Australia; ${ }^{2}$ The McCusker Alzheimer's Research Foundation, Hollywood Private Hospital, Nedlands, WA, Australia; ${ }^{3}$ The Centre of Excellence for Alzheimer's Disease Research and Care, Edith Cowan University, Joondalup, WA, Australia; ${ }^{4}$ The School of Animal Biology, University of Western Australia, Crawley, WA, Australia; ${ }^{5}$ The School of Psychology, University of Western Australia, Crawley, WA, Australia; ${ }^{6}$ Eskitis Institute for Cell and Molecular Therapies, Griffith University, Nathan, Queensland, Australia; ${ }^{7}$ Mount Sinai School of Medicine, New York, NY, USA; ${ }^{8}$ The School of Psychiatry and Clinical Neuroscience, University of Western Australia, Crawley, WA, Australia Correspondence: Professor RN Martins, The School of Medical Sciences, Edith Cowan University, 270 Joondalup Dr, Joondalup, WA 6027, Australia.
} E-mail: r.martins@ecu.edu.au

Keywords: Alzheimer's disease; cognition; cognitive decline; odor discrimination; olfactory dysfunction; smell sense

Received 4 April 2012; accepted 10 April 2012 
may affect olfactory information processing, olfactory memories usually last longer than memories formed through other sensory modalities and have more emotional valence. ${ }^{25,26}$

There is strong evidence that neuroanatomical regions involved in episodic memory, including the medial temporal lobe, are also associated with olfactory functioning. ${ }^{27,28}$ Interestingly, individuals with hippocampal lesions show significantly poorer olfactory recognition compared with odor threshold. ${ }^{29}$

Olfactory impairment is not confined to people with $A D$ or $A D$-related cognitive decline, and it has been reported in individuals suffering from other neurodegenerative diseases such as Parkinson's disease, frontotemporal dementia and Lewy body dementia. ${ }^{30-32}$ Olfactory deficits have also been reported in psychiatric disorders including schizophrenia and depression. ${ }^{33,34}$ As such, olfactory dysfunctions appear not to be specific to $A D .^{35,36}$ Further studies are needed to improve the sensitivity and specificity of olfactory screening to identify which olfactory domains are specifically affected at particular stages of preclinical AD.

We hypothesized that olfactory ability at baseline could predict altered cognitive function in a 3-year follow-up assessment. The specific questions examined by the current study were the following: (1) Is there any association between olfaction and cognition at baseline in this cohort of apparently healthy aging individuals? (2) Could baseline olfactory function predict future (3-year) cognitive decline? (3) Which olfactory domain(s) best predict cognitive alteration?

\section{Materials and methods}

Design. Participants were derived from a larger, longitudinal study, 'the Western Australia Memory Study' (for more information on this cohort, see refs 8,37-39). Participants were monitored for 3 years, and underwent annual neuropsychological, biochemical and physiological examinations. Herein, the baseline and final assessment (two-point data) results of this study will be examined. The study was approved by the Human Research Ethics Committees of the associated institutions, namely the University of Western Australia, Edith Cowan University and Hollywood Private Hospital. Participants provided informed consent before baseline assessments according to the guidelines of the National Health and Medical Research Council of Australia.

Participants. A total of 308 community-dwelling older adults aged $46-86$ years old (68\% female) were recruited from a larger study cohort. The volunteers' family members were also invited to participate. The APOE- 44 genotype was available for 273 participants, of whom $34 \%$ were $\varepsilon 4$ allele carriers ( $\varepsilon 2-\varepsilon 4$, $\varepsilon 3-\varepsilon 4$, or $\varepsilon 4-\varepsilon 4)$. The mean education level for the cohort was 13.5 years $( \pm 3.77)$, and inclusion criteria were a minimum of 6 years of education, age 45 and over, and fluency in English. Exclusion criteria for this study included: (i) a baseline score of $\leqslant 24$ in $\mathrm{MMSE}^{40}$ and $\leqslant 81$ in the Cambridge Cognitive Examination-Revised (CAMCOG$\mathrm{R}){ }^{41}$ (ii) history of anosmia or any known olfactory problems; and (iii) history or formal diagnosis of medical, neurological or psychiatric diseases and disorders affecting olfactory capacities (for example, sinunasal diseases, upper respiratory tract infection, severe head injury, Parkinson's disease, schizophrenia, and so on).

Measures. Olfactory function was assessed using the 'Extended Sniffin' Sticks' battery (Burghart, Wedel, Germany), in which odors are presented using felt-tip pen-like sticks. ${ }^{42}$ The Extended Sniffin' Sticks assess three domains of olfactory function, using threshold (T), discrimination (D) and identification (I) as three subscales and enabling calculation of a composite score, namely TDI. ${ }^{43,44}$ In this study, the Sniffin' Sticks battery was administered in a triple forced-choice staircase method as outlined previously ${ }^{45}$ and also in the test manual (Burghart).

The CAMCOG- $\mathrm{R}^{46}$ and $\mathrm{MMSE}^{40}$ were used to assess general cognitive functioning. The CAMCOG-R measures orientation, language, memory, attention, abstract thinking, praxis and calculation abilities, and provides a total score of cognitive functioning. The MMSE is commonly used as a screening measure to assess general cognitive performance in clinical and research settings. ${ }^{47}$

APOE genotyping. Blood samples were collected into different blood collection tubes including serum, EDTA (containing prostaglandin E) and heparin (Interpath Services, West VIC, Australia). The DNA was isolated from leukocytes, and APOE genotype was determined using PCR amplification and restriction enzyme digestion as previously described. ${ }^{48,49}$

Statistical analysis. All statistical analyses were performed using PASW Statistics 18 for Windows 7. Partial correlation was applied to control for the effects of age. Variables examined in this study including sex, APOE genotype, age at baseline, baseline cognitive function and olfactory performance, as measured by Sniffin' Sticks, were entered in a logistic regression model using the enter analysis model. After the completion of 3-year follow-up, participants were divided into two groups: cognitively declined and nondeclined. Participants were considered to be 'cognitively declined' if their score on the final cognitive assessment (as measured by CAMCOG-R) was $\geqslant 1$ s.d. below their baseline performance.

\section{Results}

Cohort demographics. For this study, 308 participants with a mean age of $63.06( \pm 7.25)$ years undertook neuropsychological testing. Demographic characteristics of the cohort are shown in Table 1. The scores of male/female and APOE- $\varepsilon 4$ carrier and non-carrier groups on the MMSE, Sniffin' Sticks and CAMCOG-R at baseline (Table 1) were all above the cutoff scores, as required in the exclusion criteria $(40,41,50$, respectively).

Mackay-Sim et al. ${ }^{51}$ provide guidelines for the classification of differing levels of olfactory impairment using Sniffin' Sticks: (1) severe hyposmia (a score of $\leqslant 23$ on Sniffin' Sticks TDI for women and $\leqslant 21$ for men); (2) anosmia (a TDI score of $\leqslant 16$ ); and (3) mild hyposmia (in women a score of 23-27, and in men 
Table 1 Baseline descriptive results (age, years of education, cognitive measures and olfactory function were assessed and data analyzed in terms of gender and APOE genotype; Total $N=308)$

\begin{tabular}{|c|c|c|c|c|c|c|c|}
\hline Variables & $\begin{array}{c}\text { Male } \\
(\mathrm{N}=99)\end{array}$ & $\begin{array}{c}\text { Female } \\
(\mathrm{N}=209)\end{array}$ & $\mathbf{P}$ & $\begin{array}{c}A P O E-\varepsilon 4^{a} \\
\text { non-carrier }(N=202)\end{array}$ & $\begin{array}{c}\text { APOE-₹4 carrier } \\
(\mathrm{N}=99)\end{array}$ & $\mathbf{P}$ & Total cohort \\
\hline Age & $65.19( \pm 7.59)$ & $62.05( \pm 6.88)$ & $0.000^{*}$ & $63.43( \pm 7.62)$ & $62.70( \pm 6.39)$ & 0.413 & $63.06( \pm 7.25)$ \\
\hline Education years & $14.05( \pm 4.14)$ & $13.34( \pm 3.56)$ & 0.127 & $13.58( \pm 3.91)$ & $13.41( \pm 3.43)$ & 0.713 & $13.57( \pm 3.77)$ \\
\hline MMSE & $29.05( \pm 1.12)$ & $29.20( \pm 1.09)$ & 0.281 & $29.16( \pm 1.17)$ & $29.11( \pm 0.96)$ & 0.729 & $29.15( \pm 1.10)$ \\
\hline CAMCOG-R & $98.58( \pm 3.58)$ & $98.71( \pm 3.34)$ & 0.743 & $98.75( \pm 3.50)$ & $98.49( \pm 3.12)$ & 0.536 & $98.67( \pm 3.41)$ \\
\hline SS-T & $7.03( \pm 2.58)$ & $7.58( \pm 2.34)$ & 0.063 & $7.44( \pm 2.35)$ & $7.30( \pm 2.09)$ & 0.622 & $7.40( \pm 2.37)$ \\
\hline SS-D & $11.31( \pm 2.25)$ & $11.88( \pm 2.43)$ & 0.058 & $11.83( \pm 2.37)$ & $11.49( \pm 2.41)$ & 0.260 & $11.69( \pm 2.39)$ \\
\hline SS-I & $12.64( \pm 1.80)$ & $12.49( \pm 2.04)$ & 0.539 & $12.54( \pm 1.98)$ & $12.56( \pm 1.80)$ & 0.919 & $12.54( \pm 1.96)$ \\
\hline SS-TDI & $30.67( \pm 4.53)$ & $31.72( \pm 4.63)$ & 0.061 & $31.54( \pm 4.58)$ & $31.08( \pm 4.53)$ & 0.414 & $31.38( \pm 4.62)$ \\
\hline
\end{tabular}

Abbreviations: CAMCOG-R, The Revised Cambridge Cognitive Examination; MMSE, Mini Mental State Examination; SS-D, Sniffin' Sticks discrimination; SS-I, Sniffin' Sticks identification; SS-T, Sniffin' Sticks threshold; SS-TDI, Sniffin' Sticks composite score.

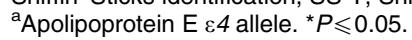

Table 2 Demographic information and baseline performance of cognitively declined ${ }^{\mathrm{a}}$ and non-declined participants

\begin{tabular}{|c|c|c|c|c|c|c|c|c|}
\hline Variables & Age & Educ. years $^{\mathrm{b}}$ & MMSE & CAMCOG-R & SS-T & SS-D & SS-I & SS-TDI \\
\hline $\begin{array}{l}\text { Non-declined } \\
(N=250)\end{array}$ & $62.59( \pm 6.98)$ & $13.65( \pm 3.65)$ & $29.20( \pm 1.11)$ & $98.63( \pm 3.28)$ & $7.53( \pm 2.32)$ & $11.90( \pm 2.21)$ & $12.62( \pm 1.91)$ & $31.79( \pm 4.13)$ \\
\hline $\begin{array}{l}\text { Declined } \\
(N=58)\end{array}$ & $65.10( \pm 8.08)$ & $13.22( \pm 4.25)$ & $28.95( \pm 1.05)$ & $98.84( \pm 3.94)$ & $6.87( \pm 2.55)$ & $10.80( \pm 2.86)$ & $12.20( \pm 2.16)$ & $29.65( \pm 6.04)$ \\
\hline$P$ & $0.017^{*}$ & 0.442 & 0.124 & 0.664 & 0.063 & $0.009^{*, c}$ & 0.153 & $0.013^{*^{, c}}$ \\
\hline
\end{tabular}

Abbreviations: CAMCOG-R, The Revised Cambridge Cognitive Examination; MMSE, Mini Mental State Examination; SS-D, Sniffin' Sticks discrimination; SS-I, Sniffin' Sticks identification; SS-T, Sniffin' Sticks threshold; SS-TDI, Sniffin' Sticks composite score.

${ }^{a}$ Cognitive decline was considered as a score $\geqslant 1$ s.d. below baseline performance on CAMCOG-R in the last assessment. ${ }^{b}$ Education years. ${ }^{c}$ Equal variance not assumed. ${ }^{*} P \leqslant 0.05$.

Table 3 Prediction of cognitive decline ${ }^{\mathrm{a}}$ using Sniffin' Sticks discrimination in multiple logistic regression analysis $(N=282)^{\mathrm{b}}$

\begin{tabular}{|c|c|c|c|c|c|c|c|c|}
\hline \multirow[t]{2}{*}{ Factors } & \multirow[t]{2}{*}{$B$} & \multirow[t]{2}{*}{ s.e. } & \multirow[t]{2}{*}{ Wald } & \multirow[t]{2}{*}{$d f$} & \multirow[t]{2}{*}{$\mathbf{P}^{*}$} & \multirow[t]{2}{*}{$O R$} & \multicolumn{2}{|c|}{$95 \%$ CI for OR } \\
\hline & & & & & & & Lower & Upper \\
\hline Sex & -0.005 & 0.340 & 0.000 & 1 & 0.988 & 0.995 & 0.511 & 1.937 \\
\hline APOE genotypes & -0.518 & 0.323 & 2.579 & 1 & 0.108 & 0.596 & 0.316 & 1.121 \\
\hline Age at baseline & 0.031 & 0.023 & 1.846 & 1 & 0.174 & 1.035 & 0.986 & 1.078 \\
\hline Education years & -0.008 & 0.042 & 0.039 & 1 & 0.843 & 0.992 & 0.912 & 1.078 \\
\hline MMSE & -0.140 & 0.132 & 1.119 & 1 & 0.290 & 0.870 & 0.617 & 1.127 \\
\hline SS-D & -0.141 & 0.066 & 4.582 & 1 & $0.032^{*}$ & 0.869 & 0.764 & 0.988 \\
\hline
\end{tabular}

Abbreviations: CAMCOG-R, The Revised Cambridge Cognitive Examination; Cl, confidence interval; MMSE, Mini Mental State Examination; OR, odds ratio; SS-D, Sniffin' Sticks discrimination.

${ }^{a}$ Cognitive decline was considered as a score $\geqslant 1$ s.d. below baseline performance on the CAMCOG-R in the last assessment. ${ }^{b} \mathrm{~N}$ was 308 ; however, only 282 were entered in the actual analysis. ${ }^{\star} P<0.05$.

a score of 21-29). In our cohort, 6.5, 1.3 and $19.5 \%$ met these criteria, respectively.

In this cohort, 194 (62.98) participants were non-smokers, 105 (34.09) were ex-smokers (with at least 2 years of abstinence) and 9 (2.93) participants were smokers. However, as there were no significant differences between the nonsmokers and other groups in any of the baseline assessments including age, education, cognitive function (as assessed by MMSE and CAMCOG-R) and olfactory assessments, we did not include smoking as a factor in this study.

Cognitive performance over time. There was no significant association between sex and cognitive decline $\left(\chi_{(1)}^{2}=0.179, P=0.672\right)$ or APOE genotypes and cognitive decline $\left(\chi_{(1)}^{2}=1.773, \quad P=0.183\right)$. Participants who were classified as declined $(n=58)$ performed more poorly on olfactory discrimination $(t=3.14 ; \mathrm{df}=286 ; P<0.05)$ and on cumulative olfactory performance $(t=1.33 ; \mathrm{df}=306 ; P<.05)$ as measured by Sniffin' Sticks TDI (Table 2). The declined group was older at baseline as compared with non-declined group $(N=250 ; t=-2.39 ; \mathrm{df}=306 ; P<0.05)$, but did not differ on other demographic variables including education and cognitive functioning as measured by MMSE and CAMCOG-R.

Analysis of the association between the variables indicated that age was negatively associated with baseline CAMCOG-R $(r=-0.171 ; P<0.01)$, Sniffin' Sticks T $(r=-0.193 ; P<0.01)$, D $(r=-0.260 ; P<0.01)$, I $(r=-0.188 ; P<0.01)$ and TDI $(r=-0.296 ; P<0.01)$. The CAMCOG-R was significantly associated with baseline Sniffin' Sticks $D(r=0.253 ; P<0.01)$, I $(r=0.271 ; P<0.01)$ and TDI $(r=0.228 ; P<0.01)$, but not with Sniffin' Sticks T $(r=-0.006 ; P<0.92)$. To control the effects of age on the associations between various variables, partial correlation was performed. Partial correlation analysis indicated that even after controlling for the effects of age, baseline CAMCOG-R was still significantly associated with 
Table 4 Predictors of cognitive decline ${ }^{\mathrm{a}}$ using Sniffin' Sticks total, composite score in multiple logistic regression analysis $(N=282)^{\mathrm{b}}$

\begin{tabular}{|c|c|c|c|c|c|c|c|c|}
\hline \multirow[t]{2}{*}{ Factors } & \multirow[t]{2}{*}{$B$} & \multirow[t]{2}{*}{ s.e. } & \multirow[t]{2}{*}{ Wald } & \multirow[t]{2}{*}{$d f$} & \multirow[t]{2}{*}{$\mathbf{P}^{\star}$} & \multirow[t]{2}{*}{$O R$} & \multicolumn{2}{|c|}{$95 \% \mathrm{Cl}$ for OR } \\
\hline & & & & & & & Lower & Lower \\
\hline $\begin{array}{l}\text { Sex } \\
\text { APOE genotypes } \\
\text { Age at baseline } \\
\text { Education years } \\
\text { MMSE } \\
\text { SS-TDI }\end{array}$ & $\begin{array}{r}0.095 \\
-0.442 \\
0.034 \\
-0.008 \\
-0.158 \\
-0.073\end{array}$ & $\begin{array}{l}0.333 \\
0.316 \\
0.022 \\
0.042 \\
0.130 \\
0.033\end{array}$ & $\begin{array}{l}0.082 \\
1.964 \\
2.296 \\
0.035 \\
1.482 \\
4.842\end{array}$ & $\begin{array}{l}1 \\
1 \\
1 \\
1 \\
1 \\
1\end{array}$ & $\begin{array}{l}0.775 \\
0.161 \\
0.130 \\
0.851 \\
0.223 \\
0.028^{\star}\end{array}$ & $\begin{array}{l}1.100 \\
0.642 \\
1.035 \\
0.992 \\
0.852 \\
0.930\end{array}$ & $\begin{array}{l}0.572 \\
0.346 \\
0.990 \\
0.914 \\
0.663 \\
0.872\end{array}$ & $\begin{array}{l}2.113 \\
1.193 \\
1.081 \\
1.077 \\
1.101 \\
0.992\end{array}$ \\
\hline
\end{tabular}

Abbreviations: CAMCOG-R, The Revised Cambridge Cognitive Examination; $\mathrm{Cl}$, confidence interval; MMSE, Mini Mental State Examination; OR, odds ratio; SS-TDI, Sniffin' Sticks composite score.

${ }^{\mathrm{a} C o g n i t i v e ~ d e c l i n e ~ w a s ~ c o n s i d e r e d ~ a s ~ a ~ s c o r e ~} \geqslant 1$ s.d. below baseline performance on the CAMCOG-R in the last assessment. ${ }^{\mathrm{b}} \mathrm{N}$ was 308 ; however, only 282 were entered in the actual analysis. ${ }^{*} P<0.05$.

Sniffin' Sticks D $(r=0.296, P<0.01), I(r=0.218, P<0.01)$ and TDI $(r=0.277, P<0.01)$. The association between baseline olfactory functions with cognitive decline after 3 years was further explored using logistic regression analysis (Tables 3 and 4). The ' $D$ ' scale was significantly associated with cognitive decline (OR $=0.869 ; P<0.05 ; 95 \% \mathrm{Cl}=0.764-0.988$ ); however, neither ' $\mathrm{T}$ ' $(\mathrm{OR}=0.916 ; P<0.192 ; 95 \% \mathrm{Cl}=0.803-$ 1.045) nor 'l' $(\mathrm{OR}=0.917 ; P<0.262 ; 95 \% \mathrm{Cl}=0.787-1.067)$ was significantly associated with cognitive decline as defined by CAMCOG-R performance in the last assessment (Table 3). Interestingly, baseline cognitive function (as measured by CAMCOG-R) and olfactory abilities showed similar trend of decline (Figure 1). However, other factors including sex, APOE genotype, age at baseline and baseline MMSE score were not significantly associated with cognitive decline in this study.

Logistic regression analysis indicated that higher Sniffin' Sticks TDI (composite) score was associated with lower risk of cognitive decline $(\mathrm{OR}=0.872 ; P<0.05 ; 95 \% \mathrm{Cl}=0.872-0.992)$ (Table 4). Other variables, including sex, APOE genotype, age, education and baseline MMSE score, did not indicate a significant predictive value with regards to cognitive decline.

\section{Discussion}

The major novel finding of the current study was that olfactory discrimination (as measured by Sniffin' Sticks D) was a significant predictor of future cognitive decline over a 3-year period. The study also confirmed a series of existing findings, demonstrating that age is associated with both cognitive and olfactory functions. However, there was a significant association between olfactory function and cognitive performance even after controlling for the effects of age, education years, $A P O E$ genotype and sex. Three olfactory functions including threshold, discrimination and identification were separately assessed in this study. Interestingly, we found that discrimination was the best predictor of cognitive decline over time. It is important to note that the cognitive changes observed were small and subtle with the study participants performing within the normal range on cognitive measures.

Interestingly, our findings do not support those of other researchers who have reported that impaired olfactory identification is a strong predictor of cognitive impairment. ${ }^{52-55}$ Wilson et al. ${ }^{56}$ further reported that impairment in olfactory identification at baseline was significantly associated with the incidence of mild cognitive impairment. It has been reported

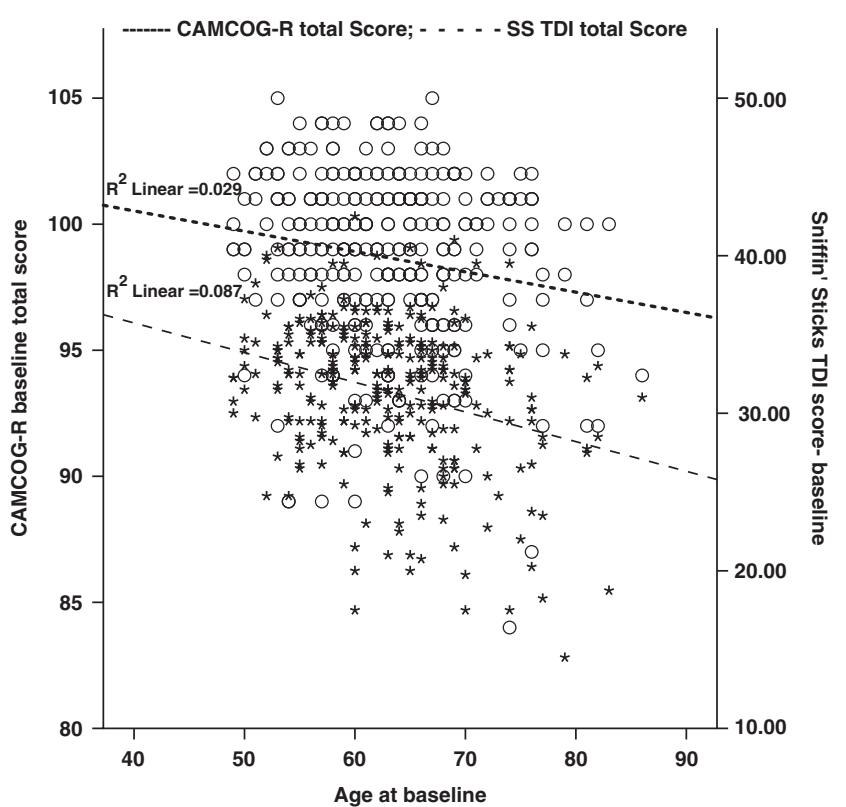

Figure 1 Dual axes graph showing the association between age, the CAMCOG-R and the Sniffin' Sticks composite score. The Cambridge Cognitive Examination-Revised (CAMCOG-R) total score; *Sniffin' Sticks TDI (composite score). The dual axes graph with linear trend lines shows the baseline performance on cognitive measure (CAMCOG-R total score) and general olfactory function (as derived from the Sniffin' Sticks composite score). Both the CAMCOG-R (upper line) and SS TDI (below the first line) linear lines show a close trend of decline over time. The mean scores were used for this graph.

that patients who were anosmic at baseline had twice the risk of developing $\mathrm{AD}$ compared with controls over a 2-year follow up, and if they had at least one $A P O E-\varepsilon 4$ allele, the risk increased to 4.9 times. $^{7}$ It should be noted that while some researchers report a significant olfactory decline in individuals positive for $A P O E-\varepsilon 4$ allele, ${ }^{6}$ others have failed to find this relationship ${ }^{8,57}$ and our current findings are consistent with these latter studies.

The reports on olfactory identification impairments in $A D$ patients and in individuals at higher risk for pathological cognitive decline are not conclusive. That is, impairment in both olfactory identification and threshold have been reported as predictive of cognitive decline and $A D^{52,55,58,59}$ One potential explanation is odor discrimination is primarily impaired in $A D$ individuals while identification problems are 
more common among patients with semantic dementia, frontotemporal dementia or corticobasal dementia. ${ }^{60}$ Another explanation for our findings is that previous studies have focused primarily, often exclusively, on odor identification and might have not extensively assessed other olfactory domains including threshold and discrimination. ${ }^{61,62}$ It has been suggested that olfactory discrimination, similar to identification, requires higher cognitive functions including working memory, judgment and decision making, and its dysfunction may represent generalized cognitive deterioration. ${ }^{63}$ Our findings support this interpretation. However, involvement of hippocampal regions in a network underlying odor discrimination $^{64}$ increases the probability of a more specific memoryrelated role in discrimination. Clearly, more studies are needed to clarify the neural regions associated with odor discrimination and cognition. As demonstrated in the present study, controlled, systematic evaluation of the various olfactory domains would contribute to more powerful assessment of the cognitive elements of odor memory and recognition, and thus also possible links to cognitive function.

The association of age with both cognitive ${ }^{65}$ and olfactory ${ }^{25}$ functions is consistent with the reports indicating that age is a significant covariate. However, the findings reported in this study indicate that the association between cognitive functions and olfactory discrimination and identification is independent of the effects of age. It has been argued that the effects of age on olfaction can be explained by the effects of cognitive decline, not age or age-related hazards affecting olfaction. ${ }^{66}$ Age, per se, may not account for the so-called age-associated olfactory dysfunction or presbyosmia, as decline in olfactory function with healthy aging seems much lower than previously reported. ${ }^{67}$ Given this, our findings support previous reports suggesting that cognitive functions, specifically those with higher verbal component, are significantly associated with olfaction. ${ }^{66,68}$

Another significant finding was the value of measuring multiple domains of olfactory functioning in predicting cognitive decline over 3 years in community-dwelling elderly individuals. Previous reports have mainly focused on the value of measuring specific olfactory domains such as identification in predicting pathological or age-related cognitive decline (for examples, see refs 17,56,69). The study reported here indicated that a comprehensive measure of olfactory function has significant power in predicting cognitive decline in healthy individuals. As various olfactory functions are to some degree reliant on threshold, ${ }^{70}$ it is necessary to assess the participants' olfactory acuity before further assessment with more specialized measures such as identification ${ }^{71}$ that may then be used for differential diagnosis or screening purposes.

The mechanisms underlying the association between olfaction and cognition have been extensively examined in the last 100 years both by psychophysics and neuroanatomical studies $(72,73$, for a review of earlier work see Herz and Engen ${ }^{74}$ ). For example, psychophysics studies have found that olfactory identification was significantly associated with semantic verbal memory, implying that the two may share some cognitive domains. ${ }^{66,75-77}$ Neuropathological studies have revealed that brain regions and subsystems involved in odor information processing, including the olfactory bulb, piriform and orbital prefrontal cortices, have direct projections to perirhinal and entorinal cortices. These, in turn, have extensive projections to the hippocampus, ${ }^{78-80}$ known as the primary brain region involved in initial memory formation, ${ }^{81-83}$ and also one of the first regions affected in AD neurodegeneration. ${ }^{84,85}$ In addition, the anterior olfactory nucleus and olfactory bulb are the two primary brain regions commonly affected in AD. ${ }^{86,87}$ Indeed, change in olfactory identification has been strongly associated with pathological changes in the medial temporal lobe structures. ${ }^{88}$ These studies strongly imply a primary role for olfactory dysfunction as an indicator of pathological cognitive decline and dementia.

The current study had some limitations that should be considered when interpreting the findings reported. First, participants were both physically and cognitively within the normal range, at least as far as it can be inferred from the MMSE, CAMCOG-R, years of education and various exclusion criteria applied during the participants recruitment phase. In addition, the participants were divided into declined/nondeclined groups based on neuropsychological measures and not a formal diagnostic clinical interview. However, the CAMCOG- $R$ is a comprehensive measure of cognitive function, and while it cannot be considered as a substitute for formal clinical evaluation of the participants, it has demonstrated high sensitivity to cognitive decline. ${ }^{89,90}$ Ideally, any future research using this cohort will examine the consistency of the reported results against formal diagnostic criteria. Also, while this study observed a significant association between olfactory $D$ and cognitive decline, it did not examine the underlying mechanisms involved in such a distinctive effect for odor differentiation as compared with other olfactory functions.

In conclusion, the association between the olfactory function and ongoing cognitive decline established in this study provides further evidence in support of the inclusion of a smell assessment alongside other neuropsychological measures in standard health screens for older adults. Many studies have reported olfactory impairments both in preclinical and clinical phases of AD. However, as noted by us and others, the predictive value of olfactory assessment in screening those at a higher risk for $A D$ needs further research ${ }^{91,92}$ to improve its sensitivity and specificity.

\section{Conflict of interest}

HRS has performed neuropsychological assessments for Pfizer and previously for Wyeth. His $\mathrm{PhD}$ was partially supported by a scholarship from the University of Western Australia. RNM is the founder and owns stock in Alzhyme. SEG is a consultant for, owns stock/options in, and/or has received lecture fees from Amicus, Diagenic, Epix, Smart Pharma and Wyeth/Elan. SEG is also a member of the data safety monitoring board for the Alzheimer Immunotherapy Alliance and holds a grant from Amicus Pharmaceuticals. The findings of this study were partially reported at the Alzheimer's Association International Conference (AA-ICAD), 2011, Paris, France.

Acknowledgements. This research was funded by the Australian National Institute of Health (Grant\# 7P01AG010491-12) and the McCusker's Alzheimer's 
Research Foundation (Project ID: 52070400). We would also like to thank A/Prof Jonathan Foster for assistance in data collection for this study.

1. Nordin S, Murphy C. Odor memory in normal aging and Alzheimer's disease. Ann $N Y$ Acad Sci 1998; 855: 686-693.

2. Doty RL, Perl DP, Steele JC, Chen KM, Pierce Jr JD, Reyes P et al. Olfactory dysfunction in three neurodegenerative diseases. Geriatrics 1991; 46(Suppl 1): 47-51.

3. Warner MD, Peabody CA, Flattery JJ, Tinklenberg JR. Olfactory deficits and Alzheimer's disease. Biol Psychiatry 1986; 21: 116-118.

4. Djordjevic J, Jones-Gotman M, De Sousa K, Chertkow H. Olfaction in patients with mild cognitive impairment and Alzheimer's disease. Neurobiol Aging 2008; 29: 693-706.

5. Lehrner J, Pusswald G, Gleiss A, Auff E, Dal-Bianco P. Odor identification and selfreported olfactory functioning in patients with subtypes of mild cognitive impairment. Clin Neuropsychol 2009; 23: 818-830.

6. Murphy C, Bacon AW, Bondi MW, Salmon DP. Apolipoprotein E status is associated with odor identification deficits in nondemented older persons. Ann N Y Acad Sci 1998; 30 744-750.

7. Graves AB, Bowen JD, Rajaram L, McCormick WC, McCurry SM, Schellenberg GD et al. Impaired olfaction as a marker for cognitive decline: interaction with apolipoprotein $\mathrm{E}$ epsilon4 status. Neurology 1999; 53: 1480-1487.

8. Sohrabi HR, Bates KA, Rodrigues M, Taddei K, Laws SM, Lautenschlager NT et al. Olfactory dysfunction is associated with subjective memory complaints in communitydwelling elderly individuals. J Alzheimers Dis 2009; 17: 135-142.

9. Wilson RS, Arnold SE, Schneider JA, Boyle PA, Buchman AS, Bennett DA. Olfactory impairment in presymptomatic Alzheimer's disease. Int Symp Olfaction Taste: Ann N Y Acad Sci 2009; 1170: 730-735.

10. Wesson DW, Levy E, Nixon RA, Wilson DA. Olfactory dysfunction correlates with amyloidbeta burden in an Alzheimer's disease mouse model. J Neurosci 2010; 30: 505-514.

11. Kovacs T, Cairns NJ, Lantos PL. Olfactory centres in Alzheimer's disease: olfactory bulb is involved in early Braak's stages. Neuroreport 2001; 12: 285-288.

12. Wilson RS, Arnold SE, Schneider JA, Tang Y, Bennett DA. The relation of cerebral Alzheimer's disease pathology to odor identification in old age. $J$ Neurol Neurosurg Psychiatry 2007; 78: 30-35.

13. Tsuboi Y, Wszolek ZK, Graff-Radford NR, Cookson N, Dickson DW. Tau pathology in the olfactory bulb correlates with Braak stage, Lewy body pathology and apolipoprotein epsilon4. Neuropathol Appl Neurobiol 2003; 29: 503-510.

14. Jellinger KA, Attems J. Alzheimer pathology in the olfactory bulb. Neuropathol Appl Neurobiol 2005; 31: 203.

15. Ghanbari HA, Ghanbari K, Harris PL, Jones PK, Kubat Z, Castellani RJ et al. Oxidative damage in cultured human olfactory neurons from Alzheimer's disease patients. Aging Cell 2004: $3: 41-44$

16. Forster S, Vaitl A, Teipel SJ, Yakushev I, Mustafa M, la Fougere C et al. Functional representation of olfactory impairment in early Alzheimer's disease. J Alzheimers Dis 2010; 22: 581-591.

17. Schubert CR, Carmichael LL, Murphy C, Klein BE, Klein R, Cruickshanks KJ. Olfaction and the 5-year incidence of cognitive impairment in an epidemiological study of older adults. $J$ Am Geriatrics Soc 2008; 56: 1517-1521.

18. Sakuma K, Nakashima K, Takahashi K. Olfactory evoked potentials in Parkinson's disease, Alzheimer's disease and anosmic patients. Psychiatry Clin Neurosci 1996; 50: 35-40.

19. Mesholam RI, Moberg PJ, Mahr RN, Doty RL. Olfaction in neurodegenerative disease: a meta-analysis of olfactory functioning in Alzheimer's and Parkinson's diseases. Arch Neurol 1998; 55: 84-90.

20. Eibenstein A, Fioretti AB, Lena C, Rosati N, Amabile G, Fusetti M. Modern psychophysical tests to assess olfactory function. Neurol Sci 2005; 26: 147-155.

21. de Wijk RA, Cain WS. Odor quality: discrimination versus free and cued identification. Percept Psychophys 1994; 56: 12-18.

22. Richardson JT, Zucco GM. Cognition and olfaction: a review. Psychol Bull 1989; 105: 352-360.

23. Schab FR. Odor memory: taking stock. Psychol Bull 1991; 109: 242-251.

24. Swan GE, Carmelli D. Impaired olfaction predicts cognitive decline in nondemented older adults. Neuroepidemiology 2002; 21: 58-67.

25. Elsner RJF. Odor memory and aging. Aging Neuropsychol Cogn 2001; 8: 284-306.

26. Stevenson RJ, Case TI, Tomiczek C. Resistance to interference of olfactory perceptual learning. Psychol Rec 2007; 57: 103-116.

27. Dade LA, Zatorre RJ, Jones-Gotman M. Olfactory learning: convergent findings from lesion and brain imaging studies in humans. Brain 2002; 125(Part 1): 86-101.

28. Buchanan TW, Tranel D, Adolphs R. A specific role for the human amygdala in olfactory memory. Learn Mem 2003; 10: 319-325.

29. Levy DA, Hopkins RO, Squire LR. Impaired odor recognition memory in patients with hippocampal lesions. Learn Memory 2004; 11: 794-796.

30. Duda JE. Olfactory system pathology as a model of Lewy neurodegenerative disease. $J$ Neurol Sci 2010; 289: 49-54.

31. McShane R, Williams SS, Williams J, Combrinck M, Christie S, Smith AD. Olfactory impairment is more marked in patients with mild dementia with Lewy bodies than those with mild Alzheimer disease. J Neurol Neurosurg Psychiatry 2009; 80: 667-670.
32. Haehner A, Boesveldt S, Berendse HW, Mackay-Sim A, Fleischmann J, Silburn PA et al. Prevalence of smell loss in Parkinson's disease: a multicenter study. Parkinsonism Relat Disord 2009; 15: 490-494.

33. Arnold SE, Smutzer GS, Trojanowski JQ, Moberg PJ. Cellular and molecular neuropathology of the olfactory epithelium and central olfactory pathways in Alzheimer's disease and schizophrenia. Ann N Y Acad Sci 1998; 855: 762-775.

34. Moberg PJ, Arnold SE, Doty RL, Gur RE, Balderston CC, Roalf DR et al. Olfactory functioning in schizophrenia: relationship to clinical, neuropsychological, and volumetric MRI measures. J Clin Exp Neuropsychol 2006; 28: 1444-1461.

35. Hawkes C. Olfaction in neurodegenerative disorder. Mov Disord 2003; 18: 364-372.

36. Burns A. Might olfactory dysfunction be a marker of early Alzheimer's disease? Lancet 2000; 355: 84-85.

37. Bates KA, Sohrabi HR, Rodrigues M, Beilby J, Dhaliwal SS, Taddei K et al. Association of cardiovascular factors and Alzheimer's disease plasma amyloid-beta protein in subjective memory complainers. J Alzheimer's Dis: JAD 2009; 17: 305-318.

38. Lau S, Bates KA, Sohrabi HR, Rodrigues M, Martins G, Dhaliwal SS et al. Functional effects of genetic polymorphism in inflammatory genes in subjective memory complainers. Neurobiol Aging 2012; 33: 1054-1056.

39. Sohrabi HR, Bates KA, Rodrigues M, Taddei K, Martins G, Laws SM et al. The relationship between memory complaints, perceived quality of life and mental health in apolipoprotein Eepsilon4 carriers and non-carriers. J Alzheimer's Dis: JAD 2009; 17: 69-79.

40. Folstein MF, Folstein SE, McHugh PR. Mini-mental state": a practical method for grading the cognitive state of patients for the clinician. J Psychiatr Res 1975; 12: 189-198.

41. Roth M, Huppert FA, Mountjoy CQ, Tym E. Cambridge Cognitive Examination-Revised (CAMCOG-R). Cambridge University Press: Cambridge, 1999.

42. Hummel T, Sekinger B, Wolf SR, Pauli E, Kobal G. 'Sniffin' sticks': olfactory performance assessed by the combined testing of odor identification, odor discrimination and olfactory threshold. Chem Senses 1997; 22: 39-52.

43. Eibenstein A, Fioretti AB, Simaskou MN, Sucapane P, Mearelli S, Mina C et al. Olfactory screening test in mild cognitive impairment. Neurol Sci 2005; 26: 156-160.

44. Hummel T, Sekinger B, Wolf SR, Pauli E, Kobal G. 'Sniffin' sticks': olfactory performance assessed by the combined testing of odor identification, odor discrimination and olfactory threshold. Chem Senses 1997; 22: 39-52.

45. Wolfensberger M, Schnieper I, Welge-Lussen A. Sniffin'Sticks: a new olfactory test battery. Acta Oto-Laryngol 2000; 120: 303-306.

46. Roth M, Huppert FA, Mountjoy CQ, Tym E. CAMDEX-R. Cambridge University Press: Cambridge, 1998.

47. Molloy DW, Standish TI. A guide to the standardized Mini-Mental State Examination. Int Psychogeriatr 1997; 9(Suppl 1): 87-94; discussion 143-50.

48. Hixson JE, Vernier DT. Restriction isotyping of human apolipoprotein $E$ by gene amplification and cleavage with Hhal. J Lipid Res 1990; 31: 545-548.

49. Wenham PR, Price WH, Blandell G. Apolipoprotein E genotyping by one-stage PCR. Lancet 1991; 337: 1158-1159.

50. Hummel T, Kobal G, Gudziol H, Mackay-Sim A. Normative data for the 'Sniffin' Sticks' including tests of odor identification, odor discrimination, and olfactory thresholds: an upgrade based on a group of more than 3,000 subjects. Eur Arch Otorhinolaryngol 2007; 264: 237-243.

51. Mackay-Sim A, Grant L, Owen C, Chant D, Silburn P. Australian norms for a quantitative olfactory function test. J Clin Neurosci 2004; 11: 874-879.

52. Suzuki Y, Yamamoto S, Umegaki H, Onishi J, Mogi N, Fujishiro H et al. Smell identification test as an indicator for cognitive impairment in Alzheimer's disease. Int $J$ Geriatr Psych 2004; 19: 727-733.

53. Stephenson R, Houghton D, Sundarararjan S, Doty RL, Stern M, Xie SX et al. Odor identification deficits are associated with increased risk of neuropsychiatric complications in patients with Parkinson's disease. Mov Disord 2010; 25: 2099-2104.

54. Velayudhan L, Lovestone S. Smell identification test as a treatment response marker in patients with Alzheimer disease receiving donepezil. J Clin Psychopharmacol 2009; 29: 387-390.

55. Wilson RS, Arnold SE, Tang Y, Bennett DA. Odor identification and decline in different cognitive domains in old age. Neuroepidemiology 2006; 26: 61-67.

56. Wilson RS, Schneider JA, Arnold SE, Tang YX, Boyle PA, Bennett DA. Olfactory identification and incidence of mild cognitive impairment in older age. Arch Gen Psychiat 2007; 64: 802-808.

57. Devanand DP, Michaels-Marston KS, Liu X, Pelton GH, Padilla M, Marder K et al. Olfactory deficits in patients with mild cognitive impairment predict Alzheimer's disease at follow-up. Am J Psychiatry 2000; 157: 1399-1405.

58. Olofsson JK, Nordin S, Wiens S, Hedner M, Nilsson LG, Larsson M. Odor identification impairment in carriers of ApoE-varepsilon4 is independent of clinical dementia. Neurobio Aging 2010; 31: 567-577.

59. Bacon AW, Bondi MW, Salmon DP, Murphy C. Very early changes in olfactory functioning due to Alzheimer's disease and the role of apolipoprotein $\mathrm{E}$ in olfaction. Ann N Y Acad Sci 1998; 855: 723-731.

60. Luzzi S, Snowden JS, Neary D, Coccia M, Provinciali L, Lambon Ralph MA. Distinct patterns of olfactory impairment in Alzheimer's disease, semantic dementia, frontotemporal dementia, and corticobasal degeneration. Neuropsychologia 2007; 45: 1823-1831.

61. Benarroch EE. Olfactory system: functional organization and involvement in neurodegenerative disease. Neurology 2010; 75: 1104-1109. 
62. Albers MW, Tabert MH, Devanand DP. Olfactory dysfunction as a predictor of neurodegenerative disease. Curr Neurol Neurosci Rep 2006; 6: 379-386.

63. Corwin J, Serby M, Rotrosen J. Olfactory deficits in AD: what we know about the nose. Neurobiol Aging 1986; 7: 580-582.

64. Martin C, Beshel J, Kay LM. An olfacto-hippocampal network is dynamically involved in odor-discrimination learning. J Neurophysiol 2007; 98: 2196-2205.

65. Salthouse TA. When does age-related cognitive decline begin? Neurobiol Aging 2009; 30 : 507-514.

66. Finkel D, Pedersen NL, Larsson M. Olfactory functioning and cognitive abilities: a twin study. J Gerontol B Psychol Sci Soc Sci 2001; 56: P226-P233.

67. Mackay-Sim A, Johnston AN, Owen C, Burne TH. Olfactory ability in the healthy population: reassessing presbyosmia. Chem Senses 2006; 31: 763-771.

68. Larsson M, Finkel D, Pedersen NL. Odor identification: influences of age, gender, cognition, and personality. J Gerontol B-Psychol 2000; 55: 304-310.

69. Wilson RS, Yu L, Schneider JA, Arnold SE, Buchman AS, Bennett DA. Lewy bodies and olfactory dysfunction in old age. Chem Senses 2011; 36: 367-373

70. Walker JC, Hall SB, Walker DB, Kendal-Reed MS, Hood AF, Niu XF. Human odo detectability: new methodology used to determine threshold and variation. Chem Senses 2003; 28: 817-826.

71. Dulay MF, Murphy C. Olfactory acuity and cognitive function converge in older adulthood: support for the common cause hypothesis. Psychol Aging 2002; 17: 392-404.

72. Engen T, Pfaffmann C. Absolute judgments of odor quality. J Exp Psychol 1960; 59: 214-219.

73. Campbell IM, Gregson RAM. Olfactory short term memory in normal, schizophrenic and brain-damaged cases. Aust J Psychol 1972; 24: 179-185.

74. Herz RS, Engen T. Odor memory: review and analysis. Psychon B Rev 1996; 3: 300-313.

75. Larsson M. Semantic factors in episodic recognition of common odors in early and late adulthood: a review. Chem Senses 1997; 22: 623-633.

76. Larsson M, Nilsson LG, Olofsson JK, Nordin S. Demographic and cognitive predictors of cued odor identification: evidence from a population-based study. Chem Senses 2004; 29: 547-554.

77. Makowska I, Kloszewska I, Grabowska A, Szatkowska I, Rymarczyk K. Olfactory deficits in normal aging and Alzheimer's disease in the polish elderly population. Arch Clin Neuropsychol 2011; 26: 270-279.

78. Eichenbaum H. Using olfaction to study memory. Ann N Y Acad Sci 1998; 855: 657-669.

79. Powell TP, Cowan WM, Raisman G. The central olfactory connexions. J Anat 1965 99(Part 4): 791-813.

80. Savic I, Gulyas B, Larsson M, Roland P. Olfactory functions are mediated by parallel and hierarchical processing. Neuron 2000; 26: 735-745
81. Riedel G, Micheau J. Function of the hippocampus in memory formation: desperately seeking resolution. Prog Neuropsychopharmacol Biol Psychiatry 2001; 25: 835-853.

82. Izquierdo I, Medina JH. Memory formation: the sequence of biochemical events in the hippocampus and its connection to activity in other brain structures. Neurobiol Learn Mem 1997; 68: 285-316.

83. Wang $\mathrm{SH}$, Morris RG. Hippocampal-neocortical interactions in memory formation, consolidation, and reconsolidation. Annu Rev Psychol 2010; 61: 49-79, C1-4.

84. Serrano-Pozo A, Frosch MP, Masliah E, Hyman BT. Neuropathological alterations in Alzheimer disease. Cold Spring Harb Perspect Biol 2011; 3: a006189.

85. Braak H, Braak E. Neuropathological stageing of Alzheimer-related changes. Acta Neuropathol 1991; 82: 239-259.

86. Averback P. Two new lesions in Alzheimer's disease. Lancet 1983; 2: 1203

87. Ohm TG, Muller H, Braak E. Calbindin-D-28k-like immunoreactive structures in the olfactory bulb and anterior olfactory nucleus of the human adult: distribution and cell typology-partial complementarity with parvalbumin. Neuroscience 1991; 42: 823-840.

88. Lojkowska W, Sawicka B, Gugala M, Sienkiewicz-Jarosz H, Bochynska A, Scinska A et al. Follow-up study of olfactory deficits, cognitive function, and volume loss of medial temporal lobe structures in patients with mild cognitive impairment. Curr Alzheimer Res 2011; 8 : 689-698.

89. Heinik J, Solomesh I. Validity of the Cambridge Cognitive Examination-Revised new Executive Function Scores in the diagnosis of dementia: some early findings. $J$ Geriatr Psychiatry Neurol 2007; 20: 22-28.

90. Verhoeven CL, Schepers VP, Post MW, van Heugten CM. The predictive value of cognitive impairments measured at the start of clinical rehabilitation for health status 1 year and 3 years poststroke. Int J Rehabil Res 2011; 34: 38-43.

91. Bahar-Fuchs A, Moss S, Rowe C, Savage G. Olfactory performance in $A D, a M C l$, and healthy ageing: a unirhinal approach. Chem Senses 2010; 35: 855-862.

92. Foster J, Sohrabi H, Verdile G, Martins R. Research criteria for the diagnosis of Alzheimer's disease: genetic risk factors, blood biomarkers and olfactory dysfunction. Int Psychogeriatr 2008; 20: 853-855.

Translational Psychiatry is an open-access journal published by Nature Publishing Group. This work is licensed under the Creative Commons Attribution-Noncommercial-No Derivative Works 3.0 Unported License. To view a copy of this license, visit http://creativecommons.org/licenses/by-nc-nd/3.0/ 